\title{
Recurrence Rate after Herniotomy only versus Discectomy in Lumbar Disc Herniation
}

\author{
Jong Soo Park', Sang Eun Choi ${ }^{2}$, Tae Koo $\mathrm{Cho}^{3}$, Sang-hyuk Kim³ ${ }^{3}$, Wootack Rhee ${ }^{3}$, \\ Woo Jae $\mathrm{Kim}^{3}$, Seong II $\mathrm{Ha}^{3}$, Jae Hyeon $\mathrm{Lim}^{3}$, II Tae Jang ${ }^{3}$ \\ ${ }^{l}$ Department of Neurosurgery, Thejoeun Hospital, Seoul, ${ }^{2}$ College of Pharmacy, Korea University, Sejong-si, \\ ${ }^{3}$ Department of Neurosurgey, Nanoori Hospital, Seoul, Korea
}

Objective: Lumbar disc herniation (LDH) recurrence necessitating reoperation can pose problems following spinal surgery, with an overall reported incidence of approximately (3-13\%). The purpose of this study is to identify the rate of recurrent disc herniation, to discuss the radiologic indications for herniotomy and to analyze clinical outcomes compared with conventional discectomy.

Methods: This study is a retrospective case control study. The authors retrospectively reviewed 114 patients who underwent herniotomy \& conventional discectomy by a single surgeon for single-level LDH between June 2009 and May 2012. Herniotomy group was 57 patients and conventional discectomy group was 57 patients that were selected from 631 patients using stratified randomization. Evaluation for LDH recurrence included detailed medical chart and radiologic review and telephone interview. Postoperative VAS and the Korean version of ODI were examined one week after surgery. Clinical outcome was investigated according to Odom's criteria from three months to three years.

Results: Of the 114 patients for whom the authors were able to definitively assess symptomatic recurrence status, four patients $(7 \%)$ experienced LDH recurrence following single-level herniotomy and three patients $(5.2 \%)$ conventional discectomy. There were no differences in the VAS and Korean version of ODI between herniotomy group and conventional discectomy group. The herniotomy group had better results than the conventional discectomy group in clinical outcome from three months to three years, but the difference was not significant.

Conclusion: There were no significant differences in clinical outcome between herniotomy and conventional discectomy. Recurrence rates following herniotomy for LDH compare favorably with those in patients who have undergone conventional discectomy, lending further support for its effectiveness in treating herniotomy.

Key Words: Lumbar Vertebrae $\cdot$ Herniated Disc $\cdot$ Diskectomy $\cdot$ Recurrence

\section{INTRODUCTION}

The introduction of microsurgical techniques in 1977 and $1978{\text { by } \text { Yasargil }^{20)} \text { and Caspar }}^{3)}$ represented an important evolution in lumbar disc surgery. Today, microsurgery is considered a standard procedure. However, since the herniated fragment was identified as the offending agent, it has always

- Received: July 22, 2013 • Revised: October 28, 2013

- Accepted: October 31, 2013

Corresponding Author: Jae Hyeon Lim, MD, PhD

Department of Neurosurgery, Seoul Nanoori Hospital, 63-8,

Nonhyun-dong, Gangnam-gu, Seoul 135-010, Korea

Tel: +82-2-3446-0098, Fax: +82-2-3448-0210

E-mail: pjs513@gmail.com

$\otimes$ This is an Open Access article distributed under the terms of the Creative Commons Attribution Non-Commercial License (http://creativecommons.org/ licenses/by-nc/3.0/) which permits unrestricted non-commercial use, distribution, and reproduction in any medium, provided the original work is properly cited. considered necessary to remove fragment only or the entire disc. This dogma is based on the assumption that increased rates of recurrent disc herniations would follow sequestrectomy alone. For the small subgroup of patients with a free fragment compressing the nerve root, Williams ${ }^{18)}$ was the first to report encouraging results following minimal removal of tissue from the intervertebral disc space. In this subpopulation $(\leq 10 \%$ of the overall population with disc herniations), other investigators confirmed success rates of greater than $90 \%$ without increased rates of reherniations in retrospective studies ${ }^{5,717)}$. Although the recurrence of lumbar disc herniation (LDH) requiring reoperation remains a controversial question in spinal surgery, the incidence of recurrent $\mathrm{LDH}$ is reported to linger around $3-13 \%$ according to several previous studies ${ }^{14)}$.

The frequency of herniotomy is gradually increasing in $\mathrm{LDH}$ treatment. Herniotomy used to be synonymous with fragmentectomy or sequestrectomy. The term 'herniotomy' is defined 
as removal of the herniated disc fragment only, and the "conventional discectomy' as removal of the herniated disc and degenerative nucleus from the intervertebral disc space. This study compared herniotomy with conventional discectomy by examining the rate of recurrent disc herniation requiring revision surgery after herniotomy. Furthermore we discussed the radiologic indications of herniotomy and analyzed differences in two procedures by comparing with the clinical outcome of conventional discectomy.

\section{MATERIALS AND METHODS}

This study is a retrospective case control study performed from June 2009 to May 2012 on single-level LDH patients. Information was gathered from the medical chart, radiologic review, and telephone interview. During three years, 57 patients underwent herniotomy by a single surgeon. 631 patients were received conventional discectomy during the same period of experimental group by the same surgeon. To minimize the biases of surgeons, we selected 57 patients as a control group who received conventional discectomy by the same surgeon. Subjects in the control group were selected using a random number generator while considering the sex and age of patients for efficiency of the study. This study protocol was reviewed and approved by our Institutional Review Board. In first postoperative week of the initial follow-up period, the postoperative VAS and the Korean version of ODI were examined. Subsequently, subjects' clinical outcomes were investigated based on Odom's criteria ${ }^{6}$ every three month for three years. Data were analyzed by independent t-test and Fisher's exact test. Null hypotheses of no difference were rejected if p-values were less than .05. SPSS 18.0 (SPSS, Inc, Chicago, IL) was used for statistical analysis.

Recurrent $\mathrm{LDH}$ was defined as a condition of reoperative

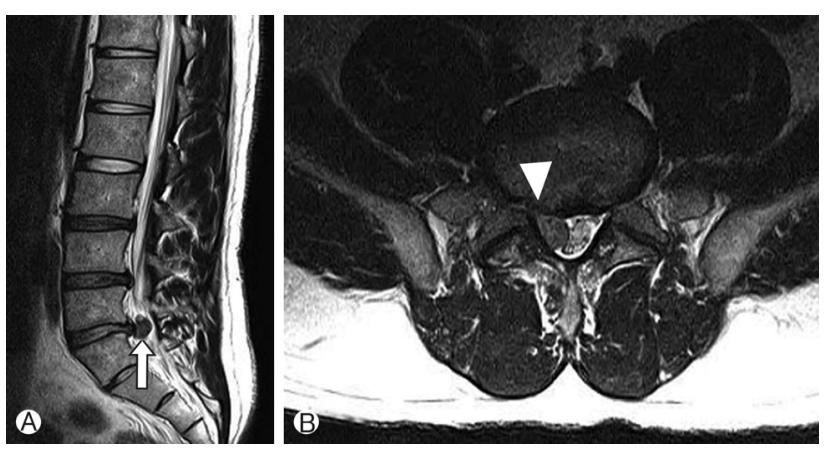

Fig. 1. Sagittal (A) and axial (B) T2-weighted MR images of hernio tomy case in lumbar disc herniation. In this case we carry out herniotomy (Arrow: low continuity with disc space, arrowhead: free fragment). sign and symptom after removal of primary lesion in immediate postoperative MR, followed by pathologic confirmation of disc herniation on enhanced MR images. We always carried out postoperative MR on $3^{\text {rd }}$ or $4^{\text {th }}$ day after surgery. So the patient that had remnant disc was excluded in this study. Reoperative sign and symptom meant that patient showed almost same condition before surgery. At that time, we rechecked MR. And we compared with rechecked MR to baseline MR. The study established the radiologic indications of herniotomy as detection of free fragment on MR scan, low continuity with disc spaces, and minimal disc protrusion of parent disc (Fig. 1). In contrast, the patient with less continuity with disc space and wide disc protrusion in MR scan underwent conventional discectomy (Fig. 2). However, the final confirmation of herniotomy was decided based on intraoperative findings.

\section{RESULTS}

Among 114 single-level LDH patients, level L4-5 was the most common level, as already known, for disc herniation in herniotomy and discectomy, followed by two levels L5-S1 and L3-4 (Table 1). We found 57 patients undergoing herniotomy and selected 57 patients undergoing conventional discectomy considering age and gender. The male to female ratios

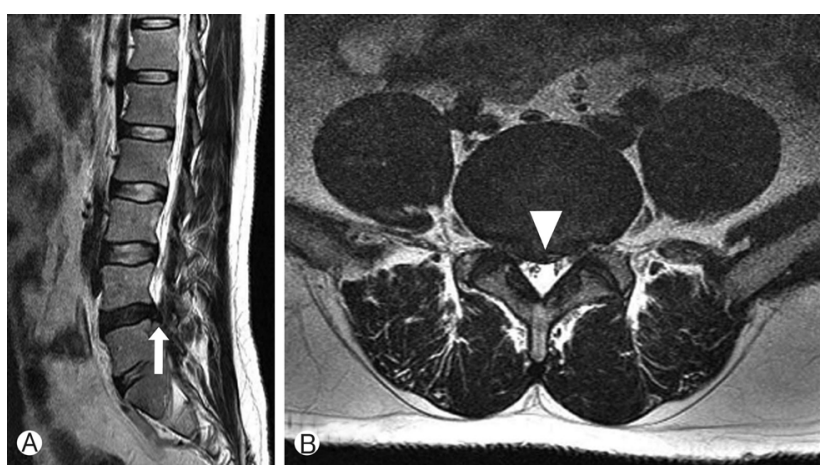

Fig. 2. Sagittal (A) and axial (B) T2-weighted MR images of conventional discectomy case in lumbar disc herniation. In this case we carry out conventional discectomy (Arrow: The continuity with disc space was shown, arrowhead: wide disc protrusion of parent disc).

Table 1. Disc level in 114 patients

\begin{tabular}{ccc}
\hline \hline Disc level & $\begin{array}{c}\text { Herniotomy } \\
N(\%)\end{array}$ & $\begin{array}{c}\text { Conventional discectomy } \\
N(\%)\end{array}$ \\
\hline L1-2 & $1(1.7 \%)$ & $0(0 \%)$ \\
L2-3 & $2(3.5 \%)$ & $2(3.5 \%)$ \\
L3-4 & $11(19.3 \%)$ & $10(17.5 \%)$ \\
L4-5 & $30(52.6 \%)$ & $29(50.8 \%)$ \\
L5-S1 & $13(22.8 \%)$ & $16(28 \%)$ \\
\hline
\end{tabular}




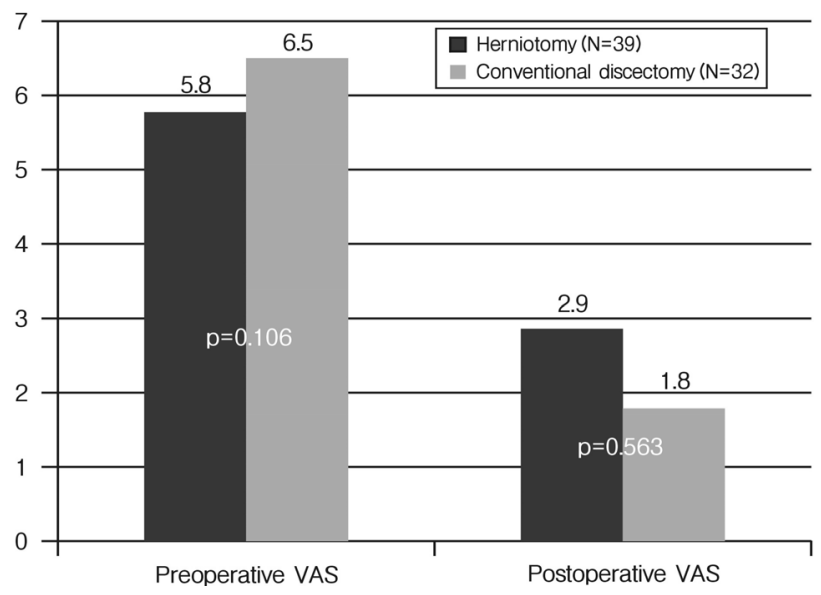

Fig. 3. Mean VAS at preoperative and postoperative one week. Bar graph demonstrating differences in pre and postoperative VAS between herniotomy and conventional discectomy. There were no significant differences. p-values are presented.

were 33:24 in herniotomy group and 31:26 in conventional discectomy group. The average ages were 50 years old in the herniotomy group and 47.6 years old in the conventional discectomy group.

There were four cases (7\%) of recurrence in the herniotomy group and three (5.7\%) in the discectomy group. Although the herniotomy group had one more case of recurrence, this was not a significant difference $(p=1.000)$. Recurrence levels ranked in the order of common cases and the average recurrent intervals were 16.5 weeks in herniotomy and 29 weeks in conventional discectomy groups (Table 2).

The VAS and Korean version of ODI of several people were unobtainable due to some data about VAS and ODI was not filled in chart. The VAS was obtained before and one week after surgery. So among the 57 subjects, 39 patients in herniotomy group and 32 patients in conventional discectomy group participated in a survey. The pre and postoperative VAS decreased from 5.8 to 2.9 points in the herniotomy group and from 6.5 to 1.8 points in the discectomy group, a greater decrease in VAS compared to the herniotomy group (Fig. 3). In Korean version of ODI, the preoperative score of 45.87 decreased to a postoperative score of 25.44 in herniotomy group. In conventional discectomy group, the preoperative score of 48.33 decreased to the postoperative score of 28.64 . Both groups showed similar levels of decrease (Fig. 4). However, no significant differences were found in VAS and Korean version of ODI outcomes between two groups (Table 3). The average follow-up period was 1.2 years when patients' conditions were confirmed through telephone interview between three months and three years postoperatively. Also results were classified based on Odom's criteria. Excellent indicated all pre-

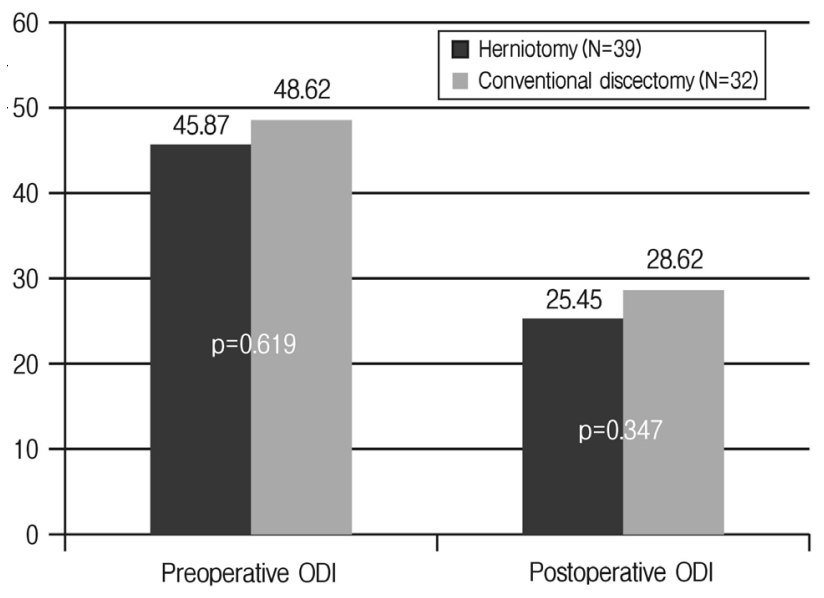

Fig. 4. Korean version of $\mathrm{ODI}$ at preoperative and postoperative 1 week, means. Bar graph demonstrating differences in Korean version of ODI between herniotomy and conventional discectomy. There were no significant differences. p-values are presented.

Table 2. Characteristics in 114 patients with LDH following herniotomy \& conventional discectomy for single-level lumbar disc herniation

\begin{tabular}{llll}
\hline \hline & Herniotomy & $\begin{array}{c}\text { Conventional } \\
\text { discectomy }\end{array}$ & p-value \\
\hline Number & 57 & 57 & \\
Male:Female & $33: 24$ & $31: 26$ & 0.570 \\
Mean age & 50 & 47.6 & 0.460 \\
Recurrence rate & $7 \%$ (4 cases) & $5.2 \%$ (3 cases) & 1.000 \\
Recurence level & L3-4:1 case, & L4-5:2 case, & \\
& L4-5:2 case, & L5-S1:1 case & \\
Mean length of time & L5-S1:1 case & & \\
to recurrence (range) & (2-5 wks wks) & 29 wks & $(13-42$ wks) \\
\hline
\end{tabular}

Table 3. Statistical analysis of VAS and Korean version of ODI score between herniotomy and conventional discectomy

\begin{tabular}{lccc}
\hline \hline & Herniotomy & $\begin{array}{c}\text { Conventional } \\
\text { discectomy }\end{array}$ & p-value \\
\hline Preoperative VAS & 5.8 & 6.5 & 0.106 \\
Postoperative VAS & 2.9 & 1.8 & 0.563 \\
Preoperative ODI & 45.87 & 48.62 & 0.619 \\
Postoperative ODI & 25.45 & 28.62 & 0.347 \\
\hline
\end{tabular}

operative symptoms relieved and abnormal findings improved. Good indicated minimal persistence of preoperative symptoms and abnormal findings unchanged or improved. Fair indicated definite relief of some preoperative symptoms and other symptoms unchanged or slightly improved. Poor indicated symptoms and signs unchanged or exacerbated. A telephone interview survey was administered to 32 out of 57 patients in the herniotomy group and 27 out of 57 patients in the discectomy 


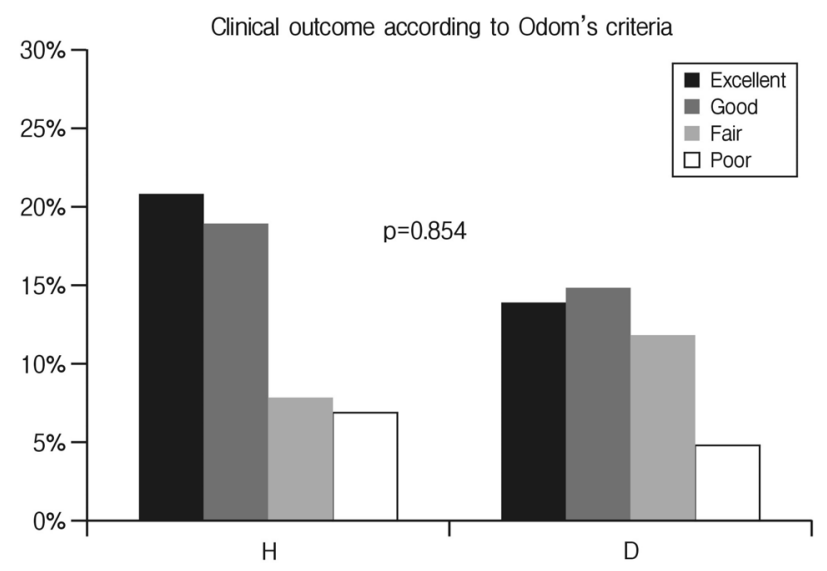

Fig. 5. Bar graph showing clinical outcome according to Odom's criteria between herniotomy $(H)$ and conventional discectomy (D), revealing no significant intergroup differences. $p$-value is presented.

Table 4. Three year outcome of herniotomy and conventional discectomy (Mean: 1.2 year after surgery)

\begin{tabular}{llrr}
\hline \hline No & Criteria & Response (ratio) & $\begin{array}{r}\text { Response (ratio) } \\
\text { discectomy }\end{array}$ \\
1 & Excellent & $12(37.5 \%)$ & $8(29.7 \%)$ \\
2 & Good & $11(34.4 \%)$ & $9(33.3 \%)$ \\
3 & Fair & $5(15.6 \%)$ & $7(25.9 \%)$ \\
4 & Poor & $4(12.5 \%)$ & $3(11.1 \%)$ \\
\hline Total & & $32 / 57(100 \%)$ & $27 / 57(100 \%)$ \\
\hline
\end{tabular}

group. This survey found 37.5\% answered excellent and 34.4 \%patients good in the herniotomy group. Similarly, 29.7\% patients answered excellent and $33.3 \%$ good in discectomy group (Table 4). There was no significant difference (p-value between the two groups according to the criteria was 0.854 . p-value in Excellent+Good vs. Fair+Poor was 0.517. Excellent vs. the others was 0.781 ) (Fig. 5).

\section{DISCUSSION}

We have described the results of the retrospective case control study for comparison of early and three years outcome after herniotomy and conventional discectomy in 114 patients with herniated lumbar discs. The repeated operation rate did not increase following removal of the herniated material only in our study. Traditionally, microdiscectomy-related neural decompression was achieved by excision of the herniated disc material, resection of as much intervertebral tissue as possible, and curettage of the endplates ${ }^{2)}$. This technique has been based on the assumption that the likelihood of reherniation would be reduced by increasing the amount of resected disc tissue ${ }^{17}$. This dogma has hardly been challenged, although scientific evidence justifying it is lacking. Complete removal of all disc material is impossible ${ }^{9,12)}$. Consequently, repeated operations could not be avoided when this approach has been used ${ }^{3,5}$. On the other hand, aggressive discectomy has been associated with reduced intervertebral height, which is thought to cause segmental instability and thus accelerate spondylosis ${ }^{4,8,10}$. This may contribute to the significant risk of failed-back surgery syndrome as well as late-onset sequelae of disc surgery after asymptomatic intervals. Although long-term studies for evaluating these sequelae are scarce, some investigators have shown that the prevalence of low-back pain in patients who do not undergo endplate curettage is reduced ${ }^{1)}$. Mochida et al. ${ }^{13)}$ confirmed that less aggressive removal of disc material might be associated with better radiographic and clinical results. Williams ${ }^{18,19)}$ introduced the concept of microsurgical removal of the offending material resulting in minimal injury to the surrounding osseous, articular, and disc structures. His technique includeed dilation of the anulus fibrosus, excision of tissue fragments "which can be easily mobilized from the intervertebral space," and visualization of the nerve root. He reported recurrence rates of 4 to $9 \%$ and a clinical success rate of $90 \%$. Several investigators have confirmed these results ${ }^{7,16,17)}$, which have been thoroughly summarized by Wenger et al. ${ }^{17)}$ The results compare favorably with those achieved after microdiscectomy (recurrence rates 3-11\%; clinical success rates 50-90\%). Rogers ${ }^{15}$, however, reported a recurrence rate of $21 \%$ (seven of 33 patients) after excision of only the herniated fragments. Unfortunately, these studies are retrospective and lack an adequate control group, thus limiting scientific power. An additional advantage of herniotomy is that abdominal or retroperitoneal injury is avoided because the disc space is not entered. Although extremely rare, these complications have been associated with devastating results ${ }^{8}$. In his 12-year review, however, Williams ${ }^{19)}$ reported that $92 \%$ of reherniations occurred within the first ${ }^{9)}$ months, and Rogers ${ }^{15)}$ indicated that most recurrences appeared within 6 months. In this study, the reoperation rate of $5.2 \%$ after conventional discectomy (three of 57 patients) seems similar to the literature. Reherniation in $7 \%$ of herniotomy treated patients is in accordance with the literature ${ }^{17}$. Regardless of the necessity for longer follow-up review, we believe that our findings provide some evidence that reherniations are not increased after herniotomy. It is interesting that the mean time to recurrence was nearly double in the conventional discectomy group ( 29 weeks versus 16.5 weeks). But there is no necessity to give a meaning because the number of recurrent patients was too small. The postoperative VAS of conventional discectomy patients group decreased more than herniotomy group. This result may be because the postoperative VAS was checked one week after surgery. There is no significant difference in VAS between groups. Also, clinical 
outcomes according Odom's criteria show less satisfaction as usual $^{11)}$. However, we expect that long-term VAS and clinical outcomes will show a better result in herniotomy group.

\section{CONCLUSION}

To conclude, herniotomy did not seem to entail a higher rate of recurrences compared with conventional discectomy. And there were no significant differences in clinical outcome between herniotomy and conventional discectomy.

\section{REFERENCES}

1. Balderston RA, Gilyard GG, Jones AA, Wiesel SW, Spengler DM, Bigos SJ, et al. The treatment of lumbar disc herniation: simple fragment excision versus disc space curettage. Journal of Spinal Disorders 4:22-25, 1991

2. Caspar W. A new surgical procedure for lumbar disc herniation causing less tissue damage through a microsurgical approach. Lumbar Disc Adult Hydrocephalus: Springer:74-80, 1977

3. Caspar W, Campbell B, Barbier DD, Kretschmmer R, Gotfried Y. The Caspar microsurgical discectomy and comparison with a conventional standard lumbar disc procedure. Neurosurgery 28:78-86, discussion 86-77, 1991

4. Cinotti C, Postacchini F: Biomechanics, in Postacchini F (ed): Lumbar Disc Herniation. Springer-Verlag (Wien):81-93, 1999

5. Davis RA. A long-term outcome analysis of 984 surgically treated herniated lumbar discs. Journal of Neurosurgery 80:415-421, 1994

6. Faldini C, Leonetti D, Nanni M, Di Martino A, Denaro L, Denaro V, Giannini S. Cervical disc herniation and cervical spondylosis surgically treated by Cloward procedure: a 10-year-minimum follow-up study. Journal of Orthopaedics and Traumatology: Official Journal of the Italian Society of Orthopaedics and Traumatology 11:99-103, 2010

7. Faulhauer K, Manicke C. Fragment excision versus conventional disc removal in the microsurgical treatment of herniated lumbar disc. Acta Neurochirurgica 133:107-111, 1995

8. Fruhwirth J, Koch G, Amann W, Hauser H, Flaschka G. Vascular complications of lumbar disc surgery. Acta Neurochirurgica 138: 912-916, 1996

9. Hudgins R. Experience with limited versus extensive disc removal in patients undergoing microsurgical operations for ruptured lumbar discs (comment). Neurosurgery 22:85, 1988

10. Kirkaldy-Willis WH, Wedge JH, Yong-Hing K, Reilly J. Pathology and pathogenesis of lumbar spondylosis and stenosis. Spine 3:319-328, 1978

11. Loupasis GA, Stamos K, Katonis PG, Sapkas G, Korres DS, Hartofilakidis G. Seven- to 20-year outcome of lumbar discectomy. Spine (Phila Pa 1976) 22:2313-2317, 1999

12. McCulloch JA. Focus issue on lumbar disc herniation: macroand microdiscectomy. Spine 21:45S-56S, 1996

13. Mochida J, Nishimura K, Nomura T, Toh E, Chiba M. The importance of preserving disc structure in surgical approaches to lumbar disc herniation. Spine 21:1556-1563; discussion 15631554, 1996

14. Moliterno JA, Knopman J, Parikh K, Cohan JN, Huang QD, Aaker GD, Grivoyannis AD, Patel AR, Härtl R, Boockvar JA. Results and risk factors for recurrence following single-level tubular lumbar microdiscectomy: Clinical article. Journal of Neurosurgery: Spine. 12:680-686, 2010

15. Rogers LA. Experience with limited versus extensive disc removal in patients undergoing microsurgical operations for ruptured lumbar discs. Neurosurgery 22:82-85, 1988

16. Striffeler H, Groger U, Reulen HJ. "Standard" microsurgical lumbar discectomy vs. "conservative" microsurgical discectomy. A preliminary study. Acta Neurochirurgica 112:62-64, 1991

17. Wenger M, Mariani L, Kalbarczyk A, Groger U. Long-term outcome of 104 patients after lumbar sequestrectomy according to Williams. Neurosurgery 49:329-334; discussion 334-325, 2001

18. Williams RW. Microlumbar discectomy: a conservative surgical approach to the virgin herniated lumbar disc. Spine 3:175-182, 1978

19. Williams RW. Microlumbar discectomy. A 12-year statistical review. Spine 11:851-852, 1986

20. Yasargil M. Microsurgical operation of herniated lumbar disc. Lumbar Disc Adult Hydrocephalus: Springer 81-81, 1977 